Agricultural Monitoring and Evaluaton Systems: What can we learn for the MRV of agricultural NAMAs?

Andreas Wilkes

Wang Shiping

Timm Tennigkeit

Feng Jiexi 



\section{Agricultural Monitoring and Evaluation Systems: What can we learn for the MRV of agricultural NAMAs?}

Andreas Wilkes ${ }^{1}$, Wang Shiping ${ }^{2}$, Timm Tennigkeit ${ }^{3}$, Feng Jiexi ${ }^{4}$

1 World Agroforestry Centre, China and East Asia Node

2 Institute of Tibetan Plateau Research, Chinese Academy of Sciences

3 Unique $\mathrm{GmbH}$

${ }^{4}$ Beijing Environmental Asset Management Consultancy Center

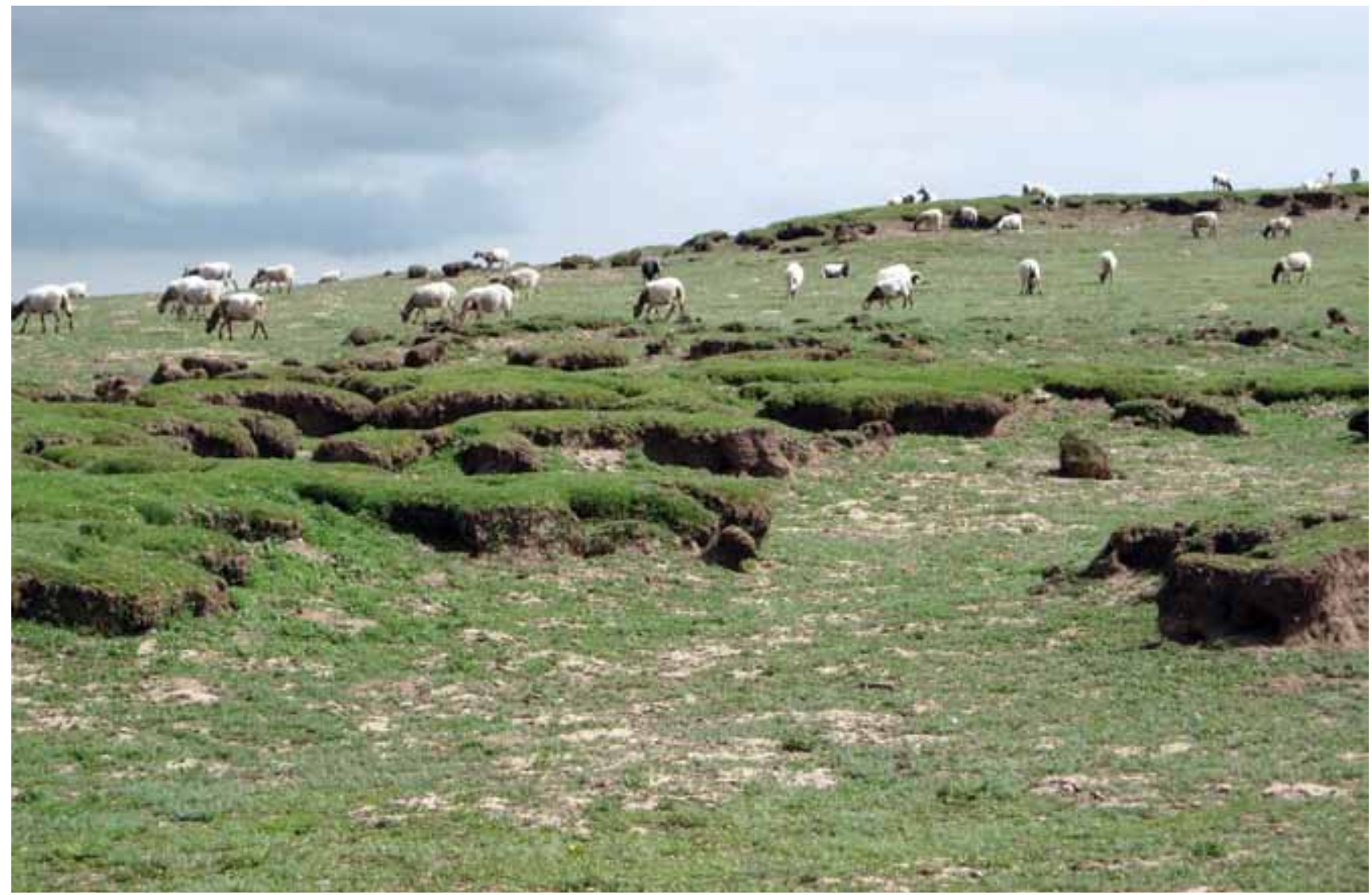

(C) ICRAF China 2011

ICRAF Working Paper No. 126 


\section{(1) \\ World Agroforestry Centre \\ TRANSFORMING LIVES AND LANDSCAPES}

\section{Correct citation \\ Wilkes, A; Wang, S; Tennigkeit T; Feng, J, 2011. Agricultural Monitoring and Evaluation Systems: What can we learn for the MRV of agricultural NAMAs?. ICRAF Working Paper No. 126, Beijing, China: World Agroforestry Centre.}

Titles in the Working Paper Series aim to disseminate interim results on agroforestry research and practices and stimulate feedback from the scientific community. Other publication series from the World Agroforestry Centre include: Agroforestry Perspectives, Technical Manuals and Occasional Papers.

Published by Nagariuna Publication (P) Ltd.

Kathmandu, Nepal

Tel: +977-1-5552118

C. World Agroforestry Centre 2011

Working Paper No. 126

ICRAF China, Beijing Office

\# 12 Zhongguancun Nan Dajie, CAAS Mailbox 195

Beijing 10081, PR China

Tel: +86-10-82 105693, fax: +86-10-82105694

Http://www.worldagroforestry.org

Http://www.chinaagroforestry.org

Layout Design: Dharma R. Maharjan, Kathmandu, Nepal

Tel: +9779841245170

Photos: Andreas Wilkes

The views expressed in this publication are those of the author(s) and not necessarily those of the World Agroforestry Centre or any other organization.

Articles appearing in this publication may be quoted or reproduced without charge, provided the source is acknowledged. All images remain the sole property of their source and may not be used for any purpose without written permission of the source. 


\section{Contents}

Abstract

Keywords

1. Introduction 3

2. Case Study: Grass Planting on the Tibetan Plateau, China 3

2.1 Grass planting programme process and institutional arrangements 4

2.2 Measurement 6

$\begin{array}{lll}2.3 \text { Reporting } & 8\end{array}$

2.3.1 Reporting system for supervision and quality management agencies 8

2.3.2 Project file management system 8

2.3.3 Project responsibility annual reporting system 8

2.4 Verification 9

3. Lessons for MRV of Agricultural NAMAs 10

$\begin{array}{ll}3.1 \text { Linking agricultural and climate MRV } & 10\end{array}$

$\begin{array}{ll}3.2 \text { The quality of agricultural MRV and MRV of agricultural NAMAs } & 12\end{array}$

4. Conclusions 13

$\begin{array}{ll}\text { References } & 14\end{array}$

Annex 1: Regulatory framework for grass planting in the Three Rivers Nature Reserve Programmes 
$5=-10 x<+2$

अ

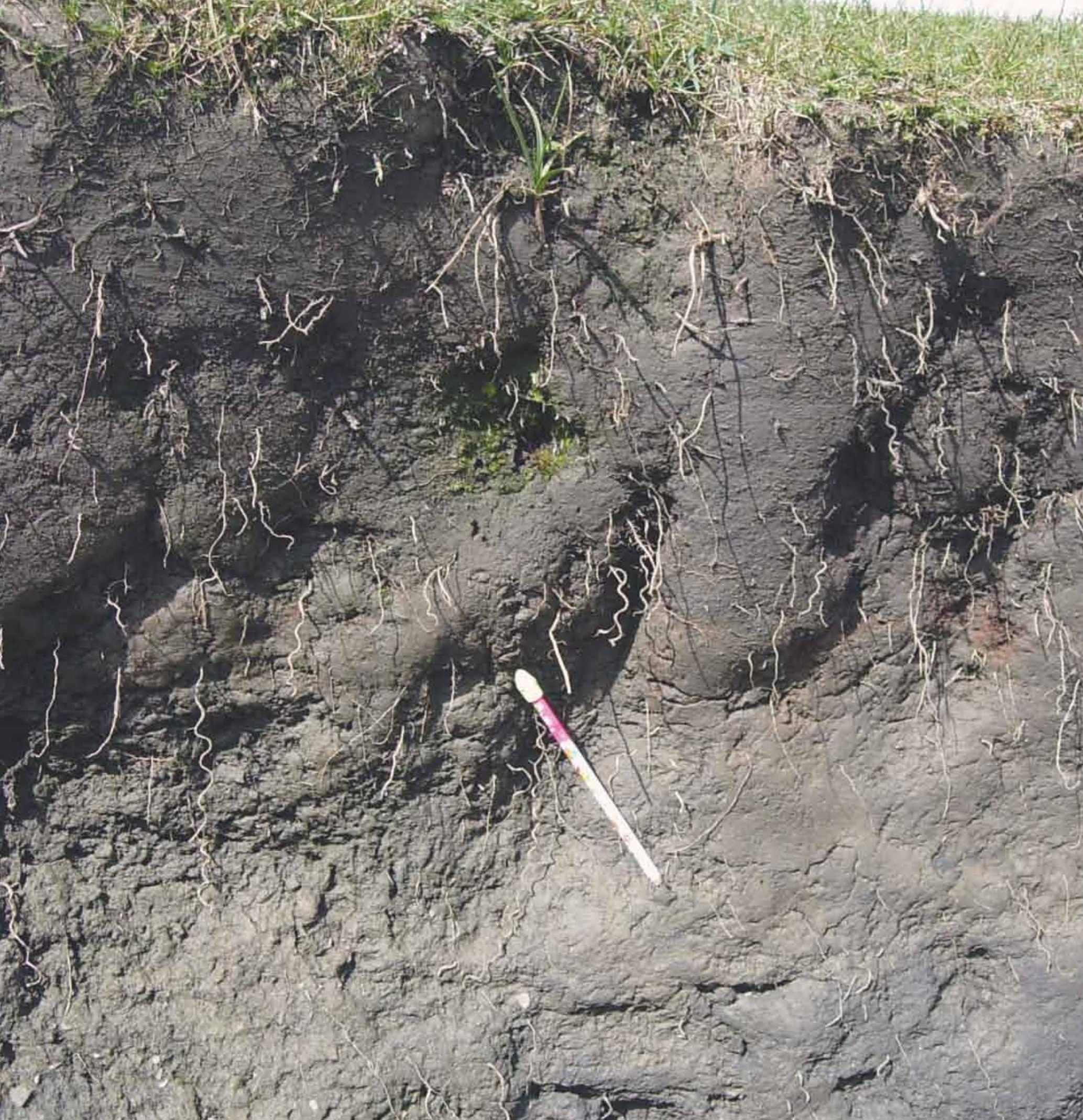

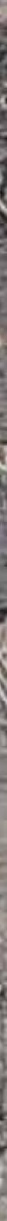

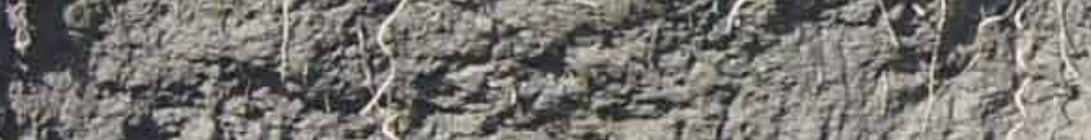

Hepenthy?

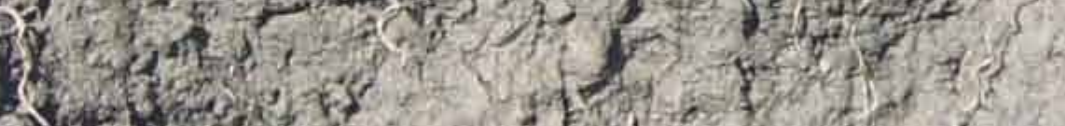

2.

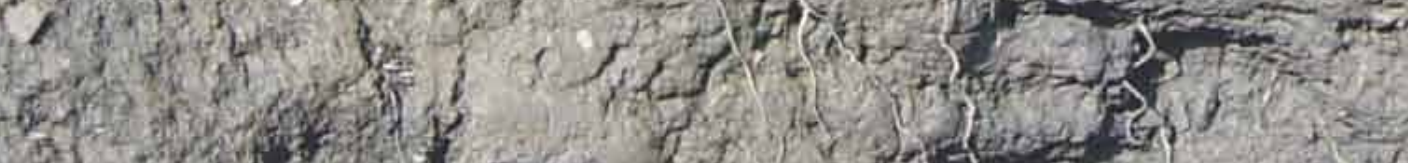
$x^{2} y^{2}-y^{2}=$

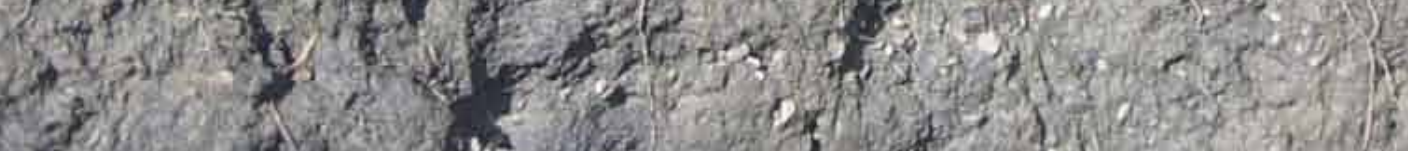
3 . N

at $2,4,3$ 


\title{
Agricultural Monitoring and Evaluation Systems: What can we learn for the MRV of agricultural NAMAs?
}

\author{
Andreas Wilkes', Wang Shiping ${ }^{2}$, Timm Tennigkeit ${ }^{3}$, Feng Jiexi ${ }^{4}$ \\ 1 World Agroforestry Centre, China and East Asia Node \\ ${ }^{2}$ Institute of Tibetan Plateau Research, Chinese Academy of Sciences \\ ${ }^{3}$ Unique $\mathrm{GmbH}$ \\ ${ }^{4}$ Beijing Environmental Asset Management Consultancy Center
}

\begin{abstract}
Mechanisms for support to Nationally Appropriate Mitigation Actions (NAMAs) have potential to upscale adoption of climate-smart agricultural practices in developing countries. Discussions of both NAMAs and agricultural mitigation have focused on methodologies for estimating emission reductions and data requirements for MRV. But the quality and credibility of NAMA MRV is also determined by institutional processes for MRV. There has been little documentation of agricultural monitoring and evaluation systems in developing countries and no previous analysis of whether they provide a credible basis for MRV of climate impacts. This paper describes an existing MRV system for a large scale grass cultivation programme in China and explores attributes of the MRV system that are consistent with the principles for credible MRV in existing UNFCCC mechanisms. Based on the case study, the paper suggests that agricultural MRV systems may be credible where (i) their procedures are encoded in explicit rules that are transparently communicated, (ii) include provisions for quality control and quality assurance, and (iii) are based on institutional arrangements that provide accountability in ways appropriate to the national context. We conclude that design of agricultural NAMAs would benefit from considering existing agricultural MRV systems and assessing the extent to which they are able to provide an institutional basis for credible MRV in national and international climate policy contexts.
\end{abstract}

\section{Keywords}

Climate change mitigation; nationally appropriate mitigation actions (NAMA); MRV; agricultural M\&E systems; grass planting 


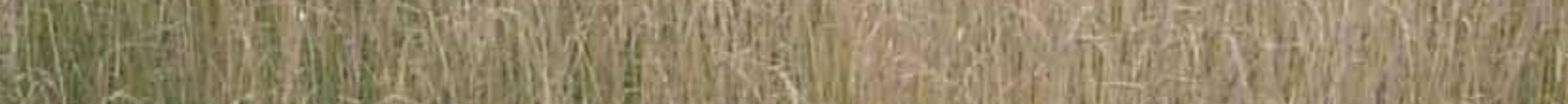

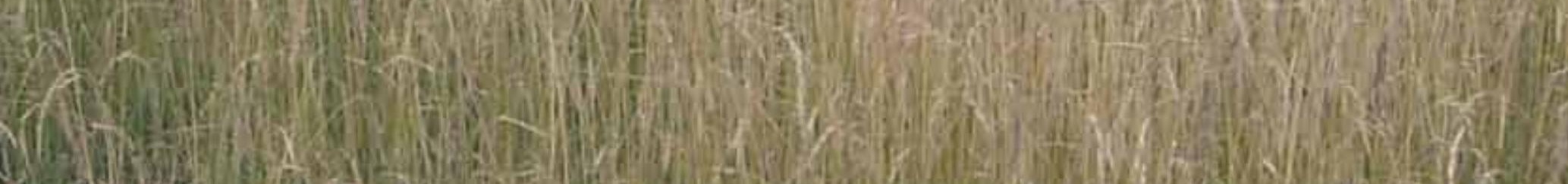
20.4.

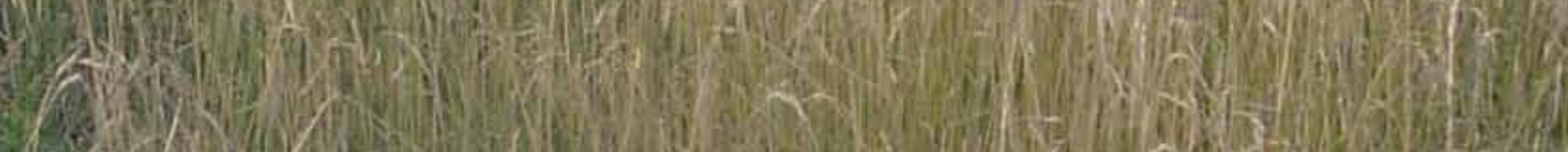
(3)

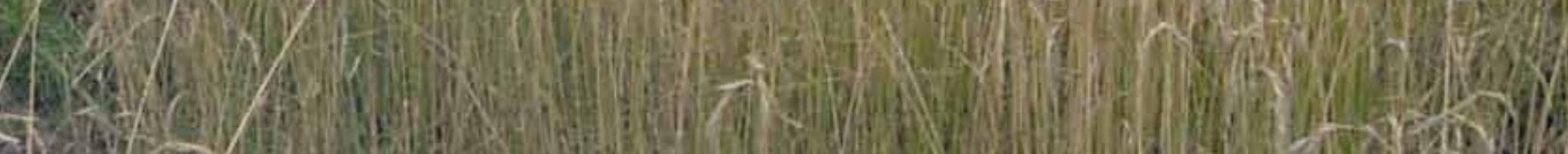

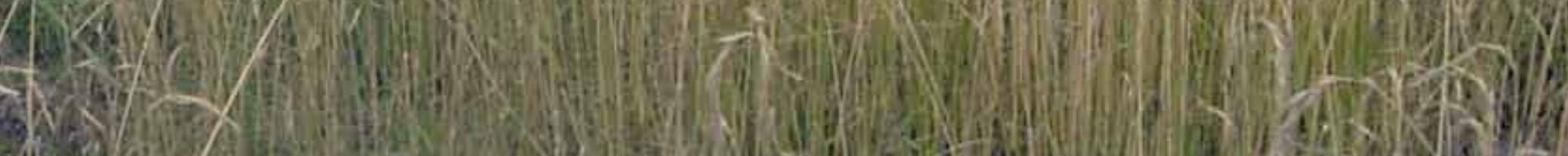

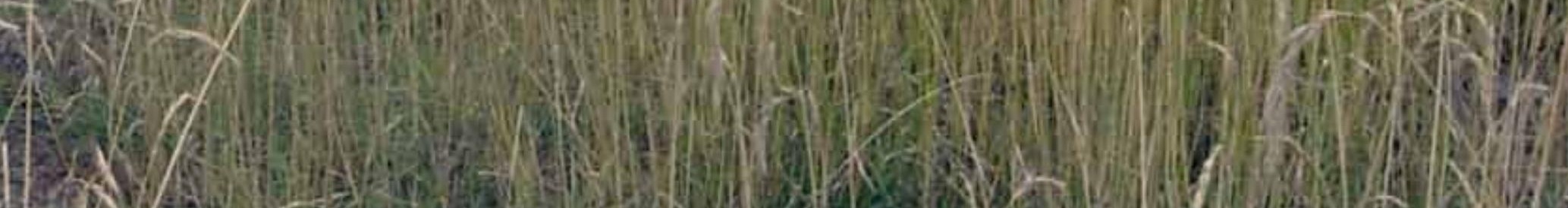
N- 


\section{Introduction}

Agriculture contributes around $14 \%$ of global anthropogenic GHGs, and its technical mitigation potential has been estimated at 5.5-6 $\mathrm{Gt} \mathrm{CO}$ e per year to 2030, mostly from soil carbon sequestration (IPCC 2007). Agriculture presents many low cost mitigation options, and considering the benefits of many mitigation practices for food security, adaptation and other agri-environmental and sustainable development objectives, it has been argued that up-scaled adoption of agricultural mitigation practices should receive more support (FAO 2009a, 2009b). Domestic and international support for nationally appropriate mitigation actions (NAMAs) represents one set of options for upscaling adoption of climate-smart' agricultural practices (FAO 2009b, Murphy et al 2009). Of 35 developing countries that submitted lists of NAMAs to UNFCCC, 15 included actions in the agriculture sector (FAO 2010).

Operational modalities for international support to NAMAs are still under discussion. Cancún saw agreement on establishing a registry to provide transparency in matching finance with needs and channeling funds. The specifics of the registry operation and procedures for measuring, reporting and verifying (MRV) the provision of finance and the climate impacts of NAMA implementation are still to be agreed (Jung et al 2011). The designs of a number of potential NAMAs in energy, transport and building sectors have been outlined (e.g. Ellermann 2009, Bakker et al 2010, Wehner et al 2010, Okubo et al 20111. ${ }^{2}$ Much of the analysis has focused on metrics and methodologies for setting reference scenarios and data requirements for MRV. In analysis of the agriculture sector, too, GHG measurement methods (e.g. C-AGG 2010) and accounting methodologies (e.g. Driver et al 2010, Murray and Baker 2010) have been widely discussed, particularly in consideration of the challenges presented by poor data availability and high uncertainty in emission factors in the sector (UNFCCC 2008, FAO 2009a).

Technical measurement of agricultural emissions and removals is just one aspect of MRV. The quality of the data collection and evaluation process itself is also a critical component of credible MRV for NAMAs (Okubo et al 2011 1). The quality of MRV is an attribute of institutional systems for MRV. Agricultural NAMAs in developing countries are most likely to be implemented through national agricultural extension systems. These systems already have some means of MRV, commonly referred to as agricultural monitoring and evaluation systems. International guidance for monitoring and evaluation (M\&E) of agricultural projects supported by the major multilateral donors is well known (e.g. Rajalahti et al 2005, IFAD 2002), but almost nothing has been documented of how existing MRV systems in developing country agriculture sectors operate. Assessment of existing agricultural MRV systems will enable informed discussion of the extent to which agricultural MRV systems can provide a credible basis for MRV of the climate impacts of scaled up adoption of climate-smart practices.

This paper presents a case study documenting an existing MRV system for a grass cultivation programme in a developing country, and uses the case study to explore attributes of agricultural MRV systems that are consistent with the need for credible MRV of climate impacts in the UNFCCC context. The example presented is the MRV system for a grass planting programme in China that is currently supported with national government funds. Section 2 presents the case study. Section 3 compares the attributes of the MRV system to principles applied to other existing UNFCCC MRV systems, and the final section discusses implications for design of agricultural NAMAs in developing countries.

\section{Case Study: Grass Planting on the Tibetan Plateau, China ${ }^{3}$}

Grassland is the dominant vegetation type on the 2.5 million sq km Tibetan Plateau in China, covering a total of around 130 million ha (Sheehy et al 2006). Official reports state that a large proportion of the Plateau's

\footnotetext{
' Climate smart agriculture is defined by FAO (2010) as "agriculture that sustainably increases productivity, resilience (adaptation), reduces/removes greenhouse gases (mitigation), and enhances achievement of national food security and development goals."

2 See also, for example, case studies at www.sectoral.org

3 This description is based on publicly available programme management documents and interviews with officials of an agriculture department in one county in Qinghai province, China.
} 
grasslands are degraded (Xinhua 2005). In Qinghai province alone, which accounts for around a quarter of the Plateau's area, officials state that $90 \%$ of grasslands are degraded to some degree (Xu 2006). 'Black beach', a form of severely degraded alpine grassland with only $50-60 \%$ of the carbon stock of undegraded grassland (Wang et al 2005), covers an estimated 7 million ha of the Plateau's area (Shang and Long 2005). Wang et al (2002) estimate that degradation of grasslands on the Tibetan Plateau has led to emissions of an average ca. 370 million $\mathrm{CCO}_{2}$ e per year over the last 30 years. Degradation of the Plateau's grasslands has become a major concern for national policy makers (e.g. State Council 1998). Planting of grass to restore degraded grasslands has been listed as a major component of China's national grassland conservation plan (MoA 2007), and ecological compensation payments for grassland restoration have been highlighted in China's 12th Five Year Plan (State Council 2011).

Given its role in protecting the headwaters of the Yangtze, Yellow and Mekong Rivers, the grasslands of Qinghai province have been singled out for particular attention. In 2000, an area of 366,000 sq km of Qinghai was gazetted as the Three Rivers Source Area National Nature Reserve. The Qinghai Three Rivers Nature Reserve Ecological Conservation and Construction Masterplan, approved in 2005, includes activities to restore degraded grasslands in the nature reserve area. By 2010, more than 50,000 ha of 'black beach' in Qinghai had been planted with grass, ${ }^{4}$ funded primarily from central government fiscal resources.

\subsection{Grass planting programme process and institutional arrangements}

Institutional arrangements and procedures for monitoring, evaluation, inspection, reporting and verification of the grass planting scheme are linked with the arrangements for planning, design and implementation. We separately describe arrangements for design and implementation, measurement, reporting, and verification.

Planning of specific activities in the grass planting programme is undertaken within the framework of a range of regulatory instruments, including the Qinghai Three Rivers Nature Reserve Ecological Conservation and Construction Masterplan (QPPG 2005), national and provincial technical standards and a number of regulations and implementation protocols which are designed to ensure the effectiveness of management of Three Rivers Nature Reserve programmes and projects. Some key regulatory documents governing the programme are listed in Annex 1.

\section{(a) Planning and design process}

Based on the targets for area planted to grass contained in medium-term plans, outline plans for annual project activities are submitted by the provincial Agriculture and Animal Husbandry Bureau (AAHB) to the finance agencies in the third quarter of each year in order to secure budget for grass planting in the coming year. Once the budget is approved, a licensed institute is contracted by the province AAHB to work with the execution agency (i.e. county AAHB) to draft an implementation plan. The implementation plan describes conditions in the project area, the planned technical approach, and the contents and scale (land area) of implementation specified for each township, village, villager group, household and each land plot. The implementation plan is submitted together with an investment budget estimate, implementation schedule, expected impacts, and outline of implementation arrangements to the provincial AAHB for approval. Once approved, institutional arrangements for implementation are put in place.

After approval of the implementation plan, the implementation agency contracts a licensed institution to draft a technical design plan, which is submitted to the province AAHB for approval. The execution agency (i.e. county AAHB) will implement according to the approved contents, scale, location and budget of this technical design plan. Annual plans and contracts are based on the approved implementation and design plans, and cannot be changed without approval from superior agencies. After approval of the technical design by the province $A A H B$, implementation through institutional arrangements outlined in the implementation plan are established through contracts with each relevant party. 


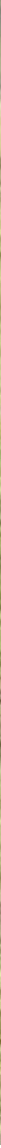

\section{(b) Institutional arrangements for implementation}

Allocation of leadership and responsibilities at each administrative level (provincial, prefecture, county and township governments) and coordination between administrative levels and line agencies are managed through a defined project institutional set-up. The province Agriculture and Animal Husbandry Bureau (AAHB) and prefecture $A A H B$ are the provincial and prefecture agencies responsible for implementation. The province, prefecture and county Three Rivers Offices are the agencies responsible for coordination of monitoring and inspection. The county government is the agency responsible for execution of the project, and it delegates responsibility for actual implementation to the county AAHB. These responsibilities are clarified and enforced through contracts signed between the relevant agencies. An independent supervision and quality management agency is also contracted, and further agencies are involved in the regulation and auditing of the use of funds.

Contract management: The implementation of the project should be done according to the contents of contracts signed between implementation, execution and material supply agencies. The contract agreements specify the rights and responsibilities of both parties to the contract. These implementation contract agreements are the main basis for the evaluation of projects. Partners to contracts must abide by all the contract contents, in order to pass inspections and evaluations. In the case of material supply contracts, to ensure quality and to lower investment costs, the grass seeds are purchased in bulk by the prefecture AAHB through a public procurement tender, ${ }^{5}$ and other inputs are bought by the county AAHB. Considering that the cultivation of pasture on black beach has some degree of technical difficulty and requires machinery, the actual execution is sub-contracted by the county $A A H B$ to the county grassland station.

${ }_{5}$ Tendering is done in accordance with the relevant tender regulations (QPPG 2006b). 
The county AAHB bureau director is defined in the project management protocols as the legal person responsible for the project. Within the administrative system, such responsibility is made explicit and enforceable through the signing of responsibility contracts with leaders of each agency. This ensures that the main leader in each agency has primary responsibility for implementation of the project and its outcomes. The bureau leaders designate a person to be responsible for the project. Within the AAHB, a 'target management system' is employed, in which the AAHB director specifies the allocation of tasks to specific individual staff members, including the quality of the work to be undertaken and progress requirements, and thus ensures that the project is implemented on time and to the quality and quantity specifications laid out in the project plans. A range of other management regulations must also be adhered to in the implementation process, such as regulations covering file management, financial management, implementation management and so on (see Annex 1).

In addition to the contracts for execution between the county government and the county AAHB (and their sub-contract with the county grassland station), the county AAHB signs responsibility contracts with the township government, and the township signs with the village committee. The village establishes a 'black beach restoration and management committee' which signs contracts for management of the specific plots with individual herders, in which the project start date and specific activities to be conducted in each plot (e.g. reseeding or cultivation of pasture) are specified.

Supervision and quality management: Ex post monitoring and inspection are treated in more detail below. During the implementation process, supervision and quality management activities are conducted. The Province Three Rivers Office is responsible for supervision and quality management. In practice it entrusts this task through tender to a licensed project supervision and quality management agency. The supervision and quality management contract that is signed is copied to the province $A A H B$, prefecture $A A H B$ and project execution agency (county AAHB). The supervision and quality management agency is required (QPPG $2006 \mathrm{~h}$ and 2006i) to designate a senior engineer to be responsible for the activity, to designate dedicated staff to undertake the supervision and quality management activities, and to make a supervision plan according to the supervision and quality management contract. The supervision and quality management implementation protocols are submitted to the prefecture and county Three Rivers Office for review and approval, and then submitted to the province AAHB and province Three Rivers Office to be put on file. The supervision and quality management personnel are responsible for quality management work during implementation, for inspecting the process of implementation on-site, inspecting such details as land surface preparation, seeding and fertilization, and during implementation should be on site to ensure that no quality problems occur.

Financial reimbursement system: Project funds are to be used strictly in accordance with the relevant fund management regulations (QPPG 2006g), in which funds are placed in a dedicated account, to be used only for the specified project. A reimbursement system is used which requires ex post reimbursement. The county Three Rivers Office works together with the county procurator, finance and audit agencies to undertake audits and inspections of the funds in order to ensure the secure use of project funds.

\subsection{Measurement}

In the context of the grass planting programme, measurement refers to the inputs and activities conducted. Black beach in the project region has a dispersed distribution, and soil structure and topography are complex. When doing the technical design, technicians go to the field sites and do onsite investigations to clarify the natural, climate, topographical and other specific features of the sites. Based on the specifics of the sites, the design agency makes a design plan for each township and village. This plan enumerates the specific sites and scale (area) required for reseeding or cultivation of pasture in the land plots of each participating household. Project execution by the county AAHB and grassland station must follow the design specified in the technical design. The location, contents, scale and standards specified cannot be changed by the county level staff at will. If problems in the implementation process occur, the county AAHB must report to the superior agency and 
Figure 1: Simplified schema of institutional arrangements for implementation

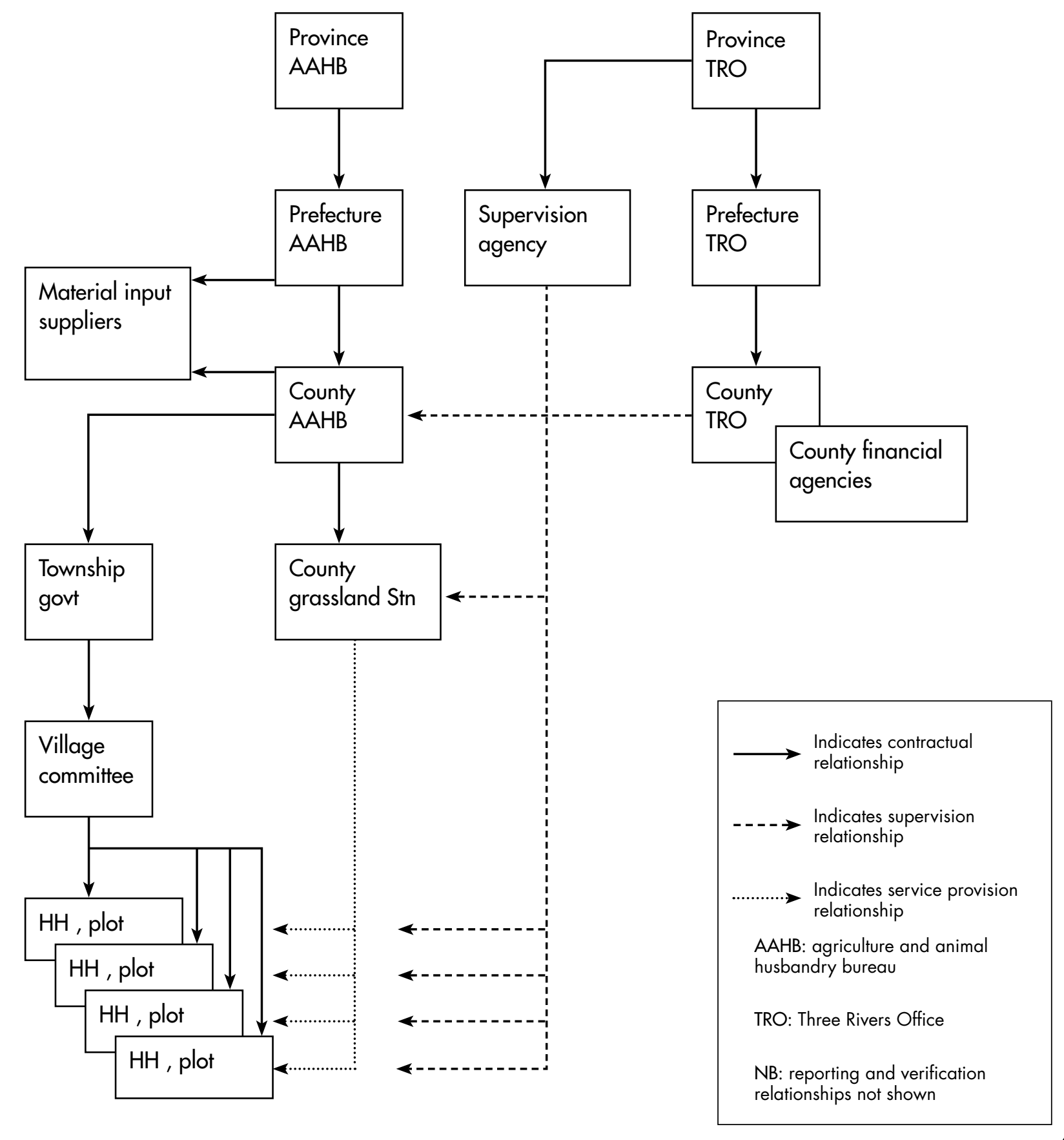

work with them to derive a solution. It is during the technical design stage, therefore, that measurement takes place, as the geographical location of each site and its boundaries are specified using a GPS so that the area of each plot is accurately recorded. The treatment of each plot is also recorded (i.e. reseeding or cultivation). A unique file number is given to each township, village, villager group and household and to each plot and the measured data is matched with the relevant file number.

Quantities of inputs (e.g. grass seed, fertilizer or fencing) are also specified in the technical design plan, based on provincial technical standards and site specific requirements. The quantities procured are recorded in procurement contracts of the prefecture and county agencies. As above, the county agencies cannot change the inputs required by the technical design plan without prior approval. 


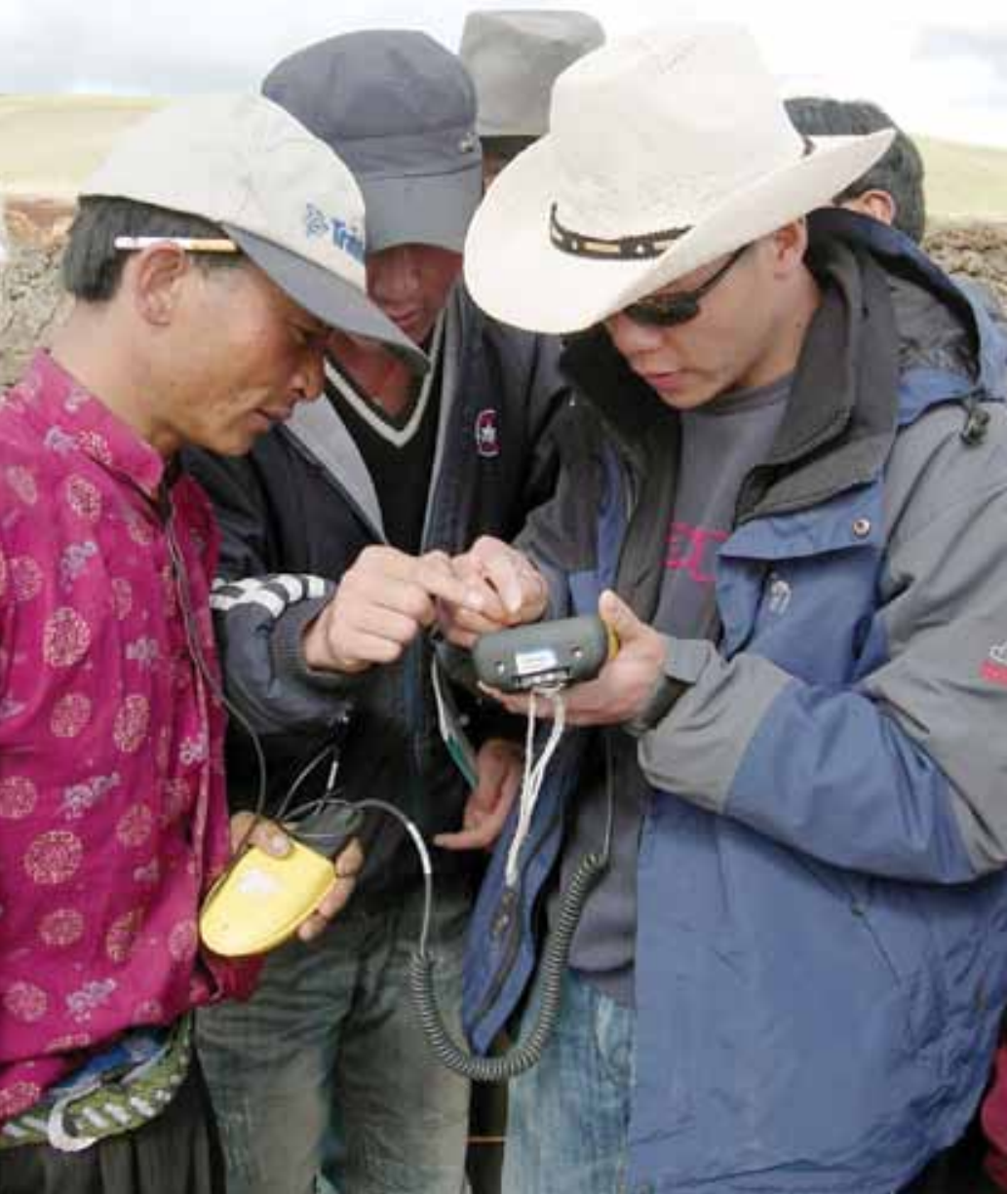

\subsection{Reporting}

\subsubsection{Reporting system for supervision and quality management agencies}

During the implementation process, the supervision and quality management agency must write and submit to the province AAHB and province Three Rivers Office a monthly, quarterly and semi-annual supervision and quality management report, and a technical report on the contents within the scope of the supervision and quality management task. When work ends within the year, the supervision agency makes an annual summary report which is also copied to the prefecture and county Three Rivers Office. Based on the investment plan sent down from the provincial departments, the supervision and quality management agency works with the prefecture and county Three Rivers Office to calculate the investment in project activities that have been completed satisfactorily, and makes a recommendation for the reimbursement of project expenses. In the final evaluation stage, the project supervision and quality management agency reviews the final evaluation report submitted by the contracting agency (county grassland station), and inspects the quality of project implementation, raising recommendations to the contracting agency for rectification of any existing problems, and finally issuing a project quality evaluation report.

\subsubsection{Project file management system}

Based on the relevant file management regulations (QPPG 2006f), a project file is set up, and a dedicated individual is allocated to be responsible for file management work. The file is the direct evidence used in the inspection and evaluation of the project. It is a basic input for project management and is a main way in which the quality of management can be assessed. The files contain all written reports, pictures, certificates and audio material related to the project. Files are kept at township and county levels. The use of information tools is encouraged. In particular, the location of project households and plots are clearly indicated on 1:25,000 maps. If files and file management are evaluated as unsatisfactory, the project cannot pass the final evaluation.

\subsubsection{Project responsibility annual reporting system}

Responsibility contracts specify that the county AAHB director is legally responsible for project outcomes. Based on the approved annual plan and related documents such as the supervision report of the supervision and quality management agency, the county AAHB makes a full evaluation of the implementation, progress and results. This includes a review of project location (township, village, group, households), scale (area), grassland type (i.e. reseeded or cultivated pasture) and inputs such as fencing, grass seeds and fertilizer and their purchasing channels, scale and the use of funds. The evaluation report also evaluates the expected ecological and economic impacts of the project. This report is kept with the project file, and submitted to the prefecture AAHB and Three Rivers Office. 


\subsection{Verification}

After the annual project and sub-project evaluations are completed, an annual verification of the project and sub-components is conducted. The main purpose of this verification is to make an overall assessment of the annual plan and the project contents, whether the project adhered to the review and approval requirements, design requirements, project management requirements and quality standards, fund use regulations and investment efficiency guidelines, and project operational management requirements.

The verification involves the prefecture and county jointly undertaking a self-inspection and the province and national level making an independent evaluation. The evaluations are done according to the regulations in QPPG (2006i). The self-inspection is comprehensive. It is the responsibility of the prefecture and county Three Rivers Office to organize the self-inspections. The superior AAHB and Grassland Stations also take part. Based on national, provincial and sectoral standards and the specific design plan, each township, village and household and plot is inspected. A special file is set up and the area of plots that pass the inspection are totaled and reported to the provincial AAHB along with an application for the provincial AAHB and Three Rivers Office to make their inspection and evaluation. On the basis of the self-inspection by the prefecture and county and the annual design plan and budget, the provincial AAHB, Three Rivers Office and other related provincial agencies undertake sample inspections of each county. The main contents of these inspections include examination of whether the responsibilities for pasture plots have been allocated clearly to households; whether the project target management system and contract responsibility systems have been implemented; whether the contents and location of the project plots adheres to the approved design plan; whether the quality adheres to national and provincial regulations and project standards; the extent to which state funds have been disbursed and their use; project implementation and technical file management and so on. More than $30 \%$ of project households are sampled through on-site inspection during the growing season, with on-site inspections examining fencing, land plot area, quality and so on. In this inspection, the error of measured plot area is controlled to within $5 \%$ on flat lands, while on slopes and in mountain areas, the error is controlled to $<20 \%$. If error is larger than this, the final reported area is based on the area measured during the verification inspection. If the area, grassland quality or other key parameters have a large error or other significant shortcomings, the work must be redone, or an economic fine is levied on the executing agency. The verification results and related information are submitted to the provincial Three Rivers Office.

Finally, the provincial Three Rivers Office and provincial Development and Reform Commission are responsible for applying to central government for an overall inspection and evaluation. The inspection and evaluation should provide the following information: project documents, approval documents, self-inspection documents, applications for inspection and evaluation; project implementation summaries; a summary of the extent to which project tasks and investment plans were completed; project design documents and maps; project evaluation financial settlement reports; financial audit reports from the audit agency; supervision and quality management reports from the supervision and quality management agency; and other documents in the project files.

Some main features of the existing MRV system for grass planting in Qinghai are summarized in Table 1. The current agricultural MRV system provides information on inputs and management activities in the establishment

\section{Table 1: Summary of MRV elements of grass planting scheme in Qinghai}

\begin{tabular}{l|l|l|l|l}
\hline What is measured & Data source & Framework reference & Reporting procedure & Verification procedure \\
\hline Inputs & $\begin{array}{l}\text { Procurement contracts } \\
\text { Project expenses }\end{array}$ & $\begin{array}{l}\text { Implementation plan, } \\
\text { budget }\end{array}$ & Annual evaluation & $\begin{array}{l}\text { Supervision } \\
\text { Annual inspection }\end{array}$ \\
\hline Activity undertaken & Project files & $\begin{array}{l}\text { Implementation plan, } \\
\text { technical design plan }\end{array}$ & Annual evaluation & $\begin{array}{l}\text { Supervision } \\
\text { Annual inspection } \\
\text { evaluation }\end{array}$ \\
\hline Land area (ha) & GPS measurement & $\begin{array}{l}\text { Implementation plan, } \\
\text { technical design plan }\end{array}$ & Annual evaluation & Sample inspections \\
\hline Quality of activity & Supervision activities & Technical standards & Supervision report & Annual inspection
\end{tabular}


of grass plots. It does not provide information on emissions or emission reductions, nor is it designed to provide continued monitoring of management activities on established grass plots which may impact on postestablishment emission reductions. The existing agricultural MRV system is currently not linked to the national emissions reporting system.

\section{Lessons for MRV of Agricultural NAMAs}

Challenges in estimating emission reductions, and in developing cost-effective MRV systems have been identified as affecting the agriculture sector (UNFCCC 2008, FAO 2009a). Internationally agreed approaches for estimating agricultural emissions exist (IPCC 2000, 2006), though their implementation in many developing country contexts will require considerable additional support (FAO2009b). Credibility of MRV in the agriculture sector will also depend on the attributes of agricultural MRV institutional arrangements and processes. These two aspects of how agricultural M\&E systems can be linked to climate MRV are discussed in the following two sections.

\subsection{Linking agricultural and climate MRV}

At a general level, the IPCC guidelines $(2000,2006)$ for estimating emissions of a given agricultural practice are based on the following general formula:

$$
E=A * E F * C F
$$

where $E$ is an estimate of total emissions from a given management practice, $A$ is activity data (e.g. total land area under a given management practice), EF is an estimate of emissions per activity (e.g. emissions per ha), and $\mathrm{CF}$ is a conversion factor for conversion of carbon or other $\mathrm{GHG}$ into $\mathrm{CO}_{2}$ equivalent units.

For measurement of a large scale programme of actions, such as a grass planting implemented in multiple locations, data on the management activities adopted is provided by the agricultural MRV (M\&E) system. In the case described in the previous section, the relevant data recorded includes: (i) area of each land plot, (ii) type of pasture established (i.e. cultivation or reseeding); (iii) quantities of agricultural inputs (e.g. fertilizer). The agricultural MRV system records the area of each land plot as measured using a GPS. The area is reported in the project files and a sample is verified during the inspection. Percentage error is specified by the verification regulations. For each land plot, the specific management practices adopted are recorded in the project files. Quantities of inputs purchased are recorded in the project files and are subject to audit and verification. The data management system therefore provides a basis for reporting management activity data and assessing its accuracy.

The IPCC (2000) defines three ways in which emission factors could be calculated and attributed to an activity such as grass planting. A Tier 1 approach would involve use of formulae and emission factors (with uncertainty estimates) specified in the relevant IPCC Guidelines. A Tier 2 approach would apply national or sub-national research results in the same calculation formulae. A Tier 3 approach would most likely not be based on direct measurements of soil carbon stock changes, but on the application of a statistical or a biogeochemical model of soil carbon response to cultivation or reseeding (Lokupitiya and Paustian 2006). Domingos (2009) and Teixeira et al. (2010) provide an example of how Tier 3 values based on research have been developed for a national grass planting programme in Portugal. In addition to carbon stock changes due to grass cultivation, emissions due to application of inputs such as fertilizer would have to be deducted from total emission reductions calculated. IPCC guidelines can be followed in making these estimates. Consistent and comparable methodologies should be applied to calculating emissions in the baseline, considering reference emission levels, and in the with-action scenario.

Both activity data and emission factors are subject to uncertainty. IPCC (2000) outlines tiered methods for uncertainty estimation. Annex 1 countries' national inventory reports (NIRs) submitted to UNFCCC have used a combination of data sources for estimating uncertainty of agricultural emissions, including Tier 1 default values 
from the IPCC guidelines, examination of other data sources and expert judgment. The IPCC (2000) requires that uncertainty estimates for each parameter are estimated at the $95 \%$ confidence interval, ${ }^{6}$ and Parties follow the principle that error should be reduced as far as is practicable. Uncertainty estimates for the mean value of agricultural emissions in Annex 1 countries' NIRs are often in the range of 13-100\%.' For an agricultural NAMA, uncertainty estimates for both activity data and emission factors would have to be derived. In the case presented in the previous section, uncertainty of land area estimates is controlled and subject to verification.

Under the UNFCCC a range of MRV systems exist and principles governing the operation of each MRV system have also been agreed. These include guidelines for the submission of national inventories (FCCC/ SBSTA/2006/9) and rules for validation and verification of CDM projects (CDM EB55/01). ${ }^{8}$ Table 2 summarizes the principles establishing the credibility of data reported through these MRV systems. Methodologies to account for emission reductions from agricultural NAMAs could also reflect these principles. Unlike CDM methodologies which are intended to be widely applicable, guidelines to be agreed for NAMAs (FCCC/CP/2010/7/Add.1, paragraphs 61 and 62) would be expected to enable MRV systems to reflect national circumstances to a greater degree while gradually aiming to achieve a consistent and comparable GHG accounting system.

Table 2: Criteria for credibility of MRV information under the UNFCCC

\begin{tabular}{|c|c|c|c|}
\hline \multicolumn{2}{|c|}{ MRV of national inventories } & \multicolumn{2}{|c|}{ MRV of CDM projects } \\
\hline Indicator & Summary & Indicator & Summary \\
\hline Transparency & $\begin{array}{l}\text { Assumptions \& methodologies used } \\
\text { are clearly explained to enable } \\
\text { informed consideration }\end{array}$ & Transparency & $\begin{array}{l}\text { Information is reported in a way } \\
\text { that allows independent validation } \\
\text { and verification }\end{array}$ \\
\hline Consistency & $\begin{array}{l}\text { The same methodology is used for } \\
\text { different years and consistent data } \\
\text { sets are used for sinks and sources }\end{array}$ & Consistency & $\begin{array}{l}\text { The same methodology is applied } \\
\text { over different periods and to similar } \\
\text { projects worldwide }\end{array}$ \\
\hline Comparability & $\begin{array}{l}\text { Same methodologies are used by } \\
\text { different Annex } 1 \text { Parties }\end{array}$ & Conservativeness & $\begin{array}{l}\text { Assumptions ensure emission } \\
\text { reductions are not over-estimated }\end{array}$ \\
\hline Completeness & $\begin{array}{l}\text { All GHG sinks and sources are } \\
\text { reported }\end{array}$ & Completeness & $\begin{array}{l}\text { All GHG sinks and sources are } \\
\text { covered or conservatively ignored }\end{array}$ \\
\hline \multirow[t]{2}{*}{ Accuracy } & $\begin{array}{l}\text { No systematic bias and uncertainty } \\
\text { reduced as far as is practical }\end{array}$ & Accuracy & $\begin{array}{l}\text { Reduce bias and uncertainty as far } \\
\text { as is practical }\end{array}$ \\
\hline & & Relevance & $\begin{array}{l}\text { All information needed to assess } \\
\text { emission reductions is reported }\end{array}$ \\
\hline
\end{tabular}

Sources: UNFCCC/SBSTA/2006/9; CDM Executive Board EB55/01.

Data on both agricultural management activities and emission factors are scarce in many developing countries (FCCC/SBI/2010/21/Add.1). For agricultural NAMAs, activity data would derive from agricultural monitoring (MRV) systems. For emission factors, the lack of long-term experimental data for many high potential agricultural mitigation practices in most developing countries implies that the extremely conservative Tier 1 emission factors would have to be used. In principle, this may be seen as an incentive to improve the availability of Tier 2 or Tier 3 data in developing countries over time. In practice, transition to Tier 2 or Tier 3 approaches requires strong research capacity and significant financial investments in long-term research (FAO 2009b), which may be unrealistic for many developing countries at present. Bakker et al (2010) provide analysis of data availability conditions that may be applicable to determining the 'MRV-ability' of actions in the agriculture sector based on the quality of available and obtainable data.

\footnotetext{
6 Under the CDM, sample surveys are required to estimate parameters to the $90 \pm 10$ precision level.

7 Based on inspection of a small sample of Annex 1 country NIRs

8 ISO 19011 describes characteristics of auditing systems which lend credibility, several of which are relevant to MRV systems.
} 


\subsection{The quality of agricultural MRV and MRV of agricultural NAMAs}

Current UNFCCC mechanisms have a range of modalities for ensuring the quality and credibility of MRV. These modalities are broadly of two types: procedures and institutions.

For national inventory reports, UNFCCC requires that NIRs report on quality control and quality assurance (QC/QA) activities, and IPCC (2000) guidelines present general guidance on how QC/QA activities can be conducted. The purpose of quality control and assurance is to assess the extent to which the relevant principles presented in Table 2 have been adhered to and to promote improvement of national inventory reporting activities. Review of NIR QC/QA procedures is included in the international reviews of NIRs conducted at the request of the UNFCCC. The conduct of these reviews in turn are also subject to guidelines (FCCC/ $\mathrm{CP} / 2002 / 8)$.

The operational modalities of the CDM, on the other hand, include also institutional measures to ensure quality and credibility, such as the requirement for independent auditing and verification of project activities (Kyoto Protocol article 12.7), which is implemented in accordance with specific guidelines (FCCC/CP/2002/8, and EB56 ${ }^{9}$ ). The Joint Implementation (JI) mechanism of the Kyoto Protocol also establishes quality and credibility largely through institutional arrangements. Eligibility for $\mathrm{Jl}$ mechanism transactions requires that an Annex 1 Party with a commitment inscribed in Annex B must have in place a national system for estimating GHG emissions and removals, and a national registry for emissions, must have submitted its most recently required inventory and have a system to record and track carbon reduction units (FCCC/KP/CMP/2005/8/Add.2). Once these institutional and procedural requirements have been met, the Party is able to verify emission reductions. KPMG (2011) has argued by analogy that NAMA eligibility could follow a similar path.

Returning to the case study presented in Section 2, we can identify the following institutional and procedural features of agricultural MRV systems which could indicate conditions for credible MRV of agricultural NAMAs:

1. An MRV system is in place: Like the rules-based approach of the CDM, written regulations stipulate the MRV procedures applied in the grass planting programme in Qinghai, and compliance is obligatory on all relevant agencies. Explicit regulations govern issues such as data management, quality supervision, reporting and verification. These regulations have force within the government administrative system.

2. MRV systems include quality control and quality assurance processes: Both data reported and the data management and reporting systems themselves are subject to inspection and verification. Data, which is the basis of any MRV system, is subject to explicit management regulations (QPPG 2006f), and uncertainty estimates of some data are explicitly regulated. The annual inspections by provincial and national agencies include examination of whether the management systems at the core of the MRV system are in place and working properly. If data and file management systems are not in good order, this is sufficient cause for a project to fail its annual inspection. Similarly, if data on sub-components, such as a plot of land, are incorrectly recorded in the files, this can also cause the sub-component to fail inspection.

3. Checks and balances in the institutional arrangements for MRV: Design, implementation, execution, supervision and verification functions are separately undertaken by different agencies. Although, since they are all government agencies, supervision and verification agencies are not totally independent (as is required of DOEs in the CDM, for instance), the agencies responsible for key supervision, inspection and verification functions are not accountable to implementation or execution agencies.

International verification of MRV systems is contentious (Levina and Helm 2009). In China, for example, the national Statistics Law may present an obstacle to fully opening MRV systems to international inspection (Teng 2009). However, communication of the national regulations governing MRV of NAMAs can enhance transparency and provide credibility. International agreement on the principles underlying national NAMA

9 http://cdm.unfccc.int/Reference/Manuals/accr_stan01.pdf 
MRV systems, combined with international consultation and analysis on the manner in which national MRV systems operate may provide credibility to the international NAMA support system while also enabling NAMA MRV systems to reflect national circumstances.

\section{Conclusions}

To date, most discussion of NAMA design has focused on data requirements and data availability for establishing baselines and estimating emission reductions. The credibility of reported data is also a product of the quality of the measurement, reporting and verification process, which is an attribute of institutional arrangements for MRV, not an attribute of the data themselves. This has been recognized in the existing UNFCCC principles and guidelines for ensuring the quality of national inventories, in the operational modalities of the CDM and the institutional requirements for Jl eligibility.

Difficulty in accessing activity data has also been identified as a constraint on agricultural inventory work in many developing countries (FCCC/SBI/2010/21/Add.1). One primary source for agricultural activity data for specific mitigation actions is the monitoring and evaluation systems employed in government agricultural agencies and public extension systems. The extent to which these systems are able to provide credible data on adoption of agricultural activities depends not only on specific procedures for data collection, but also on several attributes of the monitoring, reporting and verification system as a whole. Analysis of the case study presented in this paper suggests that agricultural MRV systems may be credible where agricultural MRV procedures are encoded in explicit rules that are transparently communicated, include provisions for quality control and quality assurance, and are based on institutional arrangements that provide accountability in ways appropriate to the national context.

Lack of data to estimate emissions factors for agricultural mitigation activities is a challenge in accounting for the climate impacts of many agricultural activities in developing countries (UNFCCC 2008, FAO 2009b). Sufficient scientific consensus already exists to determine acceptable methods for deriving new factors (IPCC 2000), and increased investment in research on agricultural emissions will gradually fill this gap. The potential to access climate finance to support implementation of NAMAs may also incentivize investment in further relevant research. Design of agricultural NAMAs will also have to consider existing agricultural MRV systems and assess the extent to which they are able to provide an institutional basis for credible MRV in national and international contexts. Basing climate MRV on existing MRV systems in the agriculture sector could reduce the transaction costs both of developing country readiness for climate MRV and the direct costs of undertaking MRV itself. 


\section{References}

Bakker, SJA; De Vita, A; Olivier, JGJ (2010) Monitoring emissions and actions in the post-2012 climate regime. Bilthoven: Netherlands Environmental Assessment Agency

Coalition on Agricultural Greenhouse Gases (C-AGG) (2010) Carbon and agriculture: Getting measurable results. Washington D.C.: Meridian Institute

CDM Executive Board. CDM Validation and Verification Manual (EB55/01). Accessible at http://cdm.unfccc. int/Reference/Manuals/accr_man01.pdf

Domingos, T (2009) Project Terraprima - Portuguese Carbon Fund: Carbon sequestration in sown biodiverse pastures. Presentation at EU side event to UNFCCC COP15 on 10 December 2009, Copenhagen

Driver, K; Haugen-Kozyra, K; Janzen, R (2010) Agriculture sector greenhouse gas practices and quantification review. M-AGG Phase 1 Report

Ellerman, C (2009) 'Exploring a sector no-lose target in the transport sector: urban transport in Beijing'. In Karen Holm Olsen, Jørgen Fenhann, Miriam Hinostroza (eds). NAMAs and the Carbon Market. Roskilde: UNEP Risøe Center

FAO (2009a) 'Enabling Agriculture to Contribute to Climate Change Mitigation'. FAO Submission to UNFCCC, February 2009

FAO (2009b) Food security and agricultural mitigation in developing countries: Options for capturing synergies. Rome: FAO

FAO (2010) Climate smart agriculture: Policies, practices and financing for food security, adaptation and mitigation. Rome: FAO

IFAD (2002) 'A guide for project M\&E. Managing for impact in rural development' (URL: http://www.ifad.org/ evaluation/guide/index.htm)

IPCC (2000) Good practice guidance and uncertainty management for national greenhouse gas inventories. Geneva: IPCC (Ch 4, Agriculture)

IPCC (2006) Guidelines for national greenhouse gas inventories for agriculture, forestry, and other land use. Geneva: IPCC

Jung, M; Eisbrenner, K; Escalante, D; de Vos, R; Höhne, N (2011) Cancún results pave the way for Nationally Appropriate Mitigation Actions [NAMAs]. EcoFys Policy Update Issue II April 2011

KPMG International Cooperative (2011) Financing low-carbon investment in developing countries: publicprivate partnerships for implementation of nationally appropriate mitigation actions. London: KPMG

Levina, E; Helm, N (2009) Nationally appropriate mitigation actions by developing countries: Architecture and key issues. Washington D.C.: Center for Clean Air Policy

Lokupitaya, A; Paustian, K (2006) 'Agricultural soil greenhouse gas emissions: A review of national inventory methods'. Journal of Environmental Quality 35:1413-1427

Ma, YS; Land, BN; Li, QY; Shi, JJ; Dong, QM (2002) 'Study on rehabilitating and rebuilding technologies for degenerated alpine meadow in the Changiiang and Yellow river source region'. Pratacultural Science 19(9): $1-5$ (in Chinese)

Ministry of Agriculture of the People's Republic of China [MoA] (2007) National grassland conservation, construction and utilization masterplan. Beijing: Ministry of Agriculture

Murphy, D; De Vit, C; Drexhage, J; Nolet, J (2009) Expanding agriculture's role in a post-2012 climate change regime. Winnipeg: IISD

Murray, BC; Baker, JS (2010) An output-based intensity approach for crediting greenhouse gas mitigation in agriculture: Explanation and policy implications. Nicholas Institute for Environmental Policy Solutions, Duke University 
Okubo, Y; Hayashi, D; Michaelowa, A (2011) 'NAMA crediting: How to assess offsets from and additionality of policy-based mitigation actions in developing countries'. Greenhouse Gas Measurement and Management, 12011 : 37-46

Rajalahti, R; Woelcke, J; Pehu, E (2005) Development of research systems to support the changing agricultural sector. World Bank agriculture and rural development discussion paper 14. Washington D.C.: World Bank

Shang, ZH; Long, RJ (2005) 'Formation causes and recovery of the "black soil type" degraded alpine grassland in Qinghai-Tibetan Plateau'. Chinese Journal of Ecology 24, 652-656 (in Chinese)

Sheehy, D; Miller, D; Johnson, D (2006) 'Transformation of traditional pastoral livestock systems on the Tibetan steppe'. Sécheresse 17 (1-2): 142-51

State Council of the PRC (1998) National ecological environment construction plan. State Council Information Office, Beijing (in Chinese).

State Council of the PRC (2011) Twelfth five year plan for China's national economic and social development. State Council, Beijing (in Chinese)

Teixeira, R; Domingos, T; Costa, A; Oliveira, R et al. (2010) 'Soil organic matter dynamics in Portuguese natural and sown rainfed grasslands'. Ecological Modelling 222(4): 993-1001

Teng, F (2009) 'Nationally appropriate mitigation actions: China's experience and perspectives'. In Karen Holm, Olsen; Jørgen, Fenhann; Miriam, Hinostroza (eds) NAMAs and the Carbon Market. UNEP Risøe Center, Roskilde

UNFCCC (2008) Challenges and opportunities for mitigation in the agricultural sector (FCCC/TP/2008/8)

Wang, G; Qian, J; Cheng, G; Lai, Y (2002) 'Soil organic carbon pool of grassland soils on the QinghaiTibetan Plateau and its global implication'. Science of the Total Environment 291: 207-217

Wang, WY; Wang, Q; Wang, CY; Shi, HL; Li, Y; Wang, G (2005) 'The effect of land management on carbon and nitrogen status in plants and soils of alpine meadows on the Tibetan Plateau'. Land Degradation \& Development, 16: 405-415

Wehner, S; Krey, M; Gusmao, F; Hayashi, D; Michaelowa, A; Sam, N (2010) Supported NAMA Design Concept for Energy-Efficiency Measures in the Mexican Residential Building Sector. Point Carbon Global Advisory Services

Xinhua News (2005) 'The negative effects of natural grassland degradation in Tibet on climate change'. Report at http://news.xinhuanet.com/newscenter/2005-08/23/content_3392417.htm. laccessed 15 November 2007)

$X u, X(2006)$ 'Problems in the conservation and utilization of grassland resources in Qinghai province and a development strategy'. Qinghai Prataculture 15(3): $21-23$ (in Chinese) 


\section{Annex 1: Regulatory framework for grass planting in the Three Rivers Nature Reserve Programmes}

\section{a) Planning framework documents}

1. QPPG 2005, "Qinghai Three Rivers Nature Reserve Ecological Conservation and Construction Masterplan", issued by Qinghai province government in 2005, approved by State Council.

b) Implementation framework documents

2. QPPG 2006a. "Qinghai Three Rivers Nature Reserve ecological protection and construction masterplan black beach integrated restoration project implementation protocols (temporary issue)"

3. QPPG 2006b. "Qinghai Three Rivers Nature Reserve ecological protection and construction project tender and bidding management temporary regulations".

4. QPPG 2006c. "Qinghai Three Rivers Nature Reserve ecological protection and construction project safety management protocols."

5. "Technical standards for black beach degraded grassland artificial reseeding vegetation establishment and its utilization and management". A provincial standard issued by Qinghai province government.

6. DB63/T390-2002 "natural grassland improvement technical standards;

7. DB63/T391-2002 "artificial pasture construction technical standards".

\section{c) Project management framework documents}

8. QPPG 2006d. "Qinghai Three Rivers Nature Reserve ecological protection and construction project management temporary implementation measures";

9. QPPG 2006e. "Qinghai Three Rivers Nature Reserve ecological protection and construction project management temporary measures";

10. QPPG 2006f. "Qinghai province Three Rivers Nature Reserve ecological protection and construction project file management method".

\section{d) Monitoring framework documents}

11. QPPG 2006g. "Qinghai three rivers nature reserve ecological protection and construction project dedicated fund monitoring management temporary method",

12. QPPG 2006h. "Qinghai Three Rivers Nature Reserve ecological protection and construction supervision and quality management management regulations",

13. QPPG 2006i. "Qinghai Three Rivers Nature Reserve ecological protection and construction project evaluation management regulations". 


\section{Who we are}

The World Agroforestry Centre is the international leader in the science and practice of integrating 'working trees' on small farms and in rural landscapes. We have invigorated the ancient practice of growing trees on farms, using innovative science for development to transform lives and landscapes.

\section{Our vision}

Our Vision is an 'Agroforestry Transformation' in the developing world resulting in a massive increase $n$ the use of working trees on working landscapes by smallholder rural households that helps ensure security in food, nutrition, income, health, shelter and energy and a regenerated environment.

\section{Our mission}

Our mission is to advance the science and practice of agroforestry to help realize an 'Agroforestry Transformation' throughout the developing world.

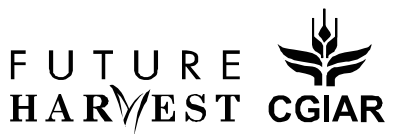

AFuture Harvest Centre supported by the CGIAR

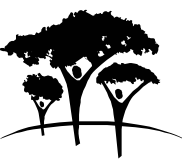

United Nations Avenue, Gigiri - PO Box 30677 - 00100 Nairobi, Kenya Tel: +254207224000 or via USA +1 6508336645

Fax: +254207224001 or via USA +1 6508336646

China and East-Asia Node Programme

c/o Kunming Institute of Botany, Heilongtan, Kuming 650204, China

Tel: +86871522 3014 - Fax: +868715216350

www.worldagroforestry.org 